\title{
Direct aortic route versus transaxillary route for transcatheter aortic valve replacement: a systematic review and meta- analysis
}

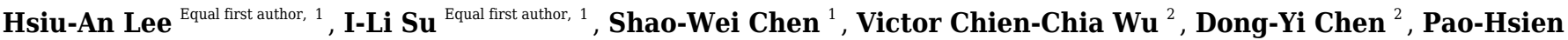 \\ Chu $^{2}{ }^{2}$, An-Hsun Chou ${ }^{3}$, Yu-Ting Cheng ${ }^{1}$, Pyng-Jing Lin ${ }^{1}$, Feng-Chun Tsai ${ }^{\text {Corresp. } 1}$ \\ ${ }^{1}$ Department of Thoracic and Cardiovascular Surgery, Chang Gung Memorial Hospital, Linkou Medical Center, Chang Gung University, Taoyuan, Taiwan \\ 2 Department of Cardiology, Chang Gung Memorial Hospital, Linkou Medical Center, Chang Gung University, Taoyuan, Taiwan \\ 3 Department of Anesthesiology, Chang Gung Memorial Hospital, Linkou Medical Center, Chang Gung University, Taoyuan, Taiwan \\ Corresponding Author: Feng-Chun Tsai \\ Email address: m8293@cgmh.org.tw
}

Background. The transfemoral route is contraindicated in nearly $10 \%$ of transcatheter aortic valve replacement (TAVR) candidates because of unsuitable iliofemoral vessels. Transaxillary (TAx) and direct aortic (DAo) routes are the principal nonfemoral TAVR routes; however, few studies have compared their outcomes.

Methods. We performed a systematic review and meta-analysis to compare the rates of mortality, stroke, and other adverse events of TAx and DAo TAVR. The study was prospectively registered with PROSPERO (registration number: CRD42017069788). We searched Medline, PubMed, Embase, and Cochrane databases for studies reporting the outcomes of DAo or TAX TAVR in at least 10 patients. Studies that did not use the Valve Academic Research Consortium definitions were excluded. We included studies that did not directly compare the 2 approaches and then pooled rates of events from the included studies for comparison.

Results. In total, 31 studies were included in the quantitative meta-analysis, with 2883 and 2172 patients in the DAo and TAx TAVR groups, respectively. Compared with TAx TAVR, DAo TAVR had a lower Society of Thoracic Surgery (STS) score, shorter fluoroscopic time, and less contrast volume use. The 30day mortality rates were significantly higher in the DAo TAVR group [9.6\%, 95\% confidence interval $(\mathrm{Cl})$ $=8.4 \%-10.9 \%$ ] than in the TAx TAVR group $(5.7 \%, 95 \% \mathrm{Cl}=4.8 \%-6.8 \% ; P$ for heterogeneity $<0.001)$. DAo TAVR was associated with a significantly lower risk of stroke in the overall study population $(2.6 \% \mathrm{vs}$ $5.8 \%, P$ for heterogeneity $<0.001)$ and in the subgroup of studies with a mean STS score of $\geq 8(1.6 \%$ vs $6.2 \%, P$ for heterogeneity $=0.005)$. DAo TAVR was also associated with lower risks of permanent pacemaker implantation $(12.3 \%$ vs. $20.1 \%, P$ for heterogeneity $=0.009)$ and valve malposition $(2.0 \%$ vs. $10.2 \%, P$ for heterogeneity $=0.023$ ) than was TAx TAVR.

Conclusions. DAo TAVR increased 30-day mortality rate compared with TAX TAVR ; by contrast, TAx TAVR increased postoperative stroke, permanent pacemaker implantation, and valve malposition risks compared with DAo TAVR. 
1 Direct aortic route versus transaxillary route for transcatheter aortic

2 valve replacement: a systematic review and meta-analysis

3

4 Hsiu-An Lee $^{1^{*}}$, I-Li Su ${ }^{1 *}$, Shao-Wei Chen ${ }^{1}$, Victor Chien-Chia $\mathrm{Wu}^{2}$, Dong-Yi Chen ${ }^{2}$, Pao-Hsien

$5 \mathrm{Chu}^{2}$, An-Hsun $\mathrm{Chou}^{3}$, Yu-Ting Cheng ${ }^{3}$, Pyng-Jing Lin ${ }^{1}$, Feng-Chun Tsai ${ }^{1}$

6

$7 \quad{ }^{1}$ Department of Thoracic and Cardiovascular Surgery, Chang Gung Memorial Hospital, Linkou

8 Medical Center, Chang Gung University, Taoyuan City, Taiwan

$9 \quad 2$ Department of Cardiology, Chang Gung Memorial Hospital, Linkou Medical Center, Chang 10 Gung University, Taoyuan City, Taiwan

$11{ }^{3}$ Department of Anesthesiology, Chang Gung Memorial Hospital, Linkou Medical Center, Chang

12 Gung University, Taoyuan City, Taiwan

13

14

${ }^{*}$ H.-A. Lee and I.-L. Su contributed equally to this work.

15

Corresponding Author:

17 Feng-Chun Tsai ${ }^{1}$

18 No. 5 Fuxing Street, Gueishan District, Taoyuan City 33305, Taiwan

19 Tel: 886-3-3281200, Fax: 886-3-3285818

20 Email address: m8293@cgmh.org.tw

21 


\section{Abstract}

23 Background. The transfemoral route is contraindicated in nearly $10 \%$ of transcatheter aortic valve replacement (TAVR) candidates because of unsuitable iliofemoral vessels. Transaxillary

25

26

27

28

29

30

31

32

33

34

35

36

37

38

39

40

41

42

43

44

45

46

47

48 (TAx) and direct aortic (DAo) routes are the principal nonfemoral TAVR routes; however, few studies have compared their outcomes.

Methods. We performed a systematic review and meta-analysis to compare the rates of mortality, stroke, and other adverse events of TAx and DAo TAVR. The study was prospectively registered with PROSPERO (registration number: CRD42017069788). We searched Medline, PubMed, Embase, and Cochrane databases for studies reporting the outcomes of DAo or TAx TAVR in at least 10 patients. Studies that did not use the Valve Academic Research Consortium definitions were excluded. We included studies that did not directly compare the 2 approaches and then pooled rates of events from the included studies for comparison.

Results. In total, 31 studies were included in the quantitative meta-analysis, with 2883 and 2172 patients in the DAo and TAx TAVR groups, respectively. Compared with TAx TAVR, DAo TAVR had a lower Society of Thoracic Surgery (STS) score, shorter fluoroscopic time, and less contrast volume use. The 30-day mortality rates were significantly higher in the DAo TAVR group $[9.6 \%, 95 \%$ confidence interval $(\mathrm{CI})=8.4 \%-10.9 \%$ ] than in the TAx TAVR group $(5.7 \%$, $95 \% \mathrm{CI}=4.8 \%-6.8 \% ; P$ for heterogeneity $<0.001)$. DAo TAVR was associated with a significantly lower risk of stroke in the overall study population $(2.6 \%$ vs $5.8 \%, P$ for heterogeneity $<0.001)$ and in the subgroup of studies with a mean STS score of $\geq 8(1.6 \% \mathrm{vs}$ $6.2 \%, P$ for heterogeneity $=0.005)$. DAo TAVR was also associated with lower risks of permanent pacemaker implantation $(12.3 \%$ vs. $20.1 \%, P$ for heterogeneity $=0.009)$ and valve malposition $(2.0 \%$ vs. $10.2 \%, P$ for heterogeneity $=0.023)$ than was TAx TAVR.

Conclusions. DAo TAVR increased 30-day mortality rate compared with TAx TAVR; by contrast, TAx TAVR increased postoperative stroke, permanent pacemaker implantation, and valve malposition risks compared with DAo TAVR. 


\section{Introduction}

50 Transcatheter aortic valve replacement (TAVR) enables the safe and effective treatment of

51

52

53

54

55

56

57

58

59

60

61

62

63

64

65

66

67

68

69

70

71

72

73

74

75

76

77

78

79

80

81

82

83

84

85

86

87 inoperable or high-surgical-risk patients with severe aortic valve disease, without using a cardiopulmonary bypass (Kodali et al., 2012; Makkar et al., 2012). Randomized controlled trials have demonstrated that TAVR is an effective alternative to surgical aortic valve replacement in intermediate-risk patients (Leon et al., 2016; Reardon et al., 2017).

TAVR is more favorable than surgical aortic valve replacement when using transfemoral (TF) access (Gargiulo et al., 2016), which is thus used as the default approach for performing TAVR in numerous institutions. However, peripheral vascular occlusion, stenosis, calcification, or tortuosity precludes TF access in approximately 10\% of patients (Grover et al., 2017), necessitating the use of an alternative route, such as transapical (TA), transaxillary (TAx), direct aortic (DAo), and transcarotid routes. To select the optimal treatment technique in patients unsuitable for TF TAVR, clinicians need to understand the outcomes of using different nonfemoral routes.

TA route was the first alternative TAVR route developed for patients with unsuitable iliofemoral vessels (Grover et al., 2017; Walther et al., 2015). However, the procedure is associated with relatively high rates of bleeding, ventricular damage (Al-Attar et al., 2009), myocardial injury (Ribeiro et al., 2015a), and mortality (Fröhlich et al., 2015; Panchal et al., 2014). DAo and TAx routes are also principal alternatives to TF; both have results comparable to those of the TF route (Adamo et al., 2015; Arai et al., 2016; Chandrasekhar et al., 2015; Fröhlich et al., 2015). However, data comparing the outcomes of using the DAo and TAx TAVR routes are limited. Therefore, we conducted this systematic review and meta-analysis to compare the morbidity and mortality associated with these 2 approaches.

\section{Materials \& Methods}

\section{Literature Search}

This systematic review of published studies was performed following the Preferred Reporting Items for Systematic Reviews and Meta-Analyses (PRISMA) guidelines, with a PRISMA checklist provided as Supplementary Table 1. This study has been prospectively registered with PROSPERO (registration number: CRD42017069788). A computerized search of the Medline, PubMed, Embase, and Cochrane databases was performed to identify all relevant studies published before July 2017 by using the following keywords: "transcatheter," "aortic valve," "TAVR," "TAVI," "direct aortic," “transaortic," "transaxillary," "axillary," "trans-subclavian," and "subclavian." The exact string of keywords is reported in Supplementary Material 1. Review articles or meta-analyses were not included for analysis, but their citations and references were searched for additional relevant studies. Citations were screened at the title and abstract levels and retrieved as a full report if outcome data of TAVRs were provided. Two evaluators (H.A. Lee and S.W. Chen) independently searched for and reviewed the articles. Discrepancies were discussed and resolved through consensus. 
88

89

90

91

92

93

94

95

96

97

98

99

100

101

102

103

104

105

106

107

108

109

110

111

112

113

114

115

116

117

118

119

120

121

122

123

124

125

126

127

\section{Study Selection}

Inclusion criteria were as follows: (1) original article in English with full-length content available, (2) at least 10 consecutive patients who underwent either DAo or TAx TAVR, (3) outcomes defined using the Valve Academic Research Consortium (VARC) definition (as VARC-1 or VARC-2) (Kappetein et al., 2012; Leon et al., 2011), and (4) separate results for patients undergoing DAo TAVR or TAx TAVR. Exclusion criteria were as follows: (1) overlapping patients or subgroup studies of the main study, (2) studies that focused on the valvein-valve procedure, (3) studies that focused on TAVR combined with another procedure, and (4) the use of devices other than Medtronic CoreValve (MCV; Medtronic, Minneapolis, MN, USA) and Edwards Valve (EV; Edwards Lifesciences, Irvine, CA, USA). Studies that did not directly compare the 2 approaches were also included. The most recent publications were retained when 2 or more similar studies were reported by the same institution or author.

\section{Data Extraction}

Relevant information was collected by H.A. Lee and S.W. Chen. The study-level characteristics extracted were first author name, publication year, study type (e.g., single-centered or multicentered), number of studies, location, study period, route (DAo or TAx), patient number, and VARC version (Table 1). The arm-level characteristics items extracted included age, logistic EuroSCORE, Society of Thoracic Surgery (STS) score, comorbidities, previous cardiac surgery, left ventricular ejection fraction, and devices (Table 2). Data on the primary and secondary outcomes for either DAo or TAx were also collected.

\section{Outcome Measures}

The primary outcomes were 30-day stroke and mortality rates after TAx or DAo TAVR. These results were further stratified by mean STS scores of $<8$ and $\geq 8$ after TAx or DAo TAVR. The 30-day stroke rates after MCV and EV use were also compared. If a study did not report the 30day mortality or stroke rates, in-hospital mortality or stroke rates were used. The secondary outcomes were device success, conversion to traditional surgery, valve malposition, acute kidney injury, major bleeding, major vascular complication, new permanent pacemaker (PPM) implantation, paravalvular leakage (PVL) grade of $\geq 2$, 30-day cardiovascular mortality, and 1year mortality.

\section{Quality Assessment}

We assessed the quality of the included studies by using the Newcastle-Ottawa Scale (NOS) (Wells et al., 2014). Quality scores ranged from 0 (lowest) to 8 (highest). The NOS was applied to each article separately by H.A. Lee and S.W. Chen and disagreements were resolved by consensus between the 2 reviewers.

\section{Statistical Analysis}

Peer] reviewing PDF | (2019:09:41000:1:0:NEW 25 Mar 2020) 
128 This meta-analysis included studies that did not directly compare the 2 approaches and pooled

129

130

131

132

133

134

135

136

137

138

139

140

141

142

143

144

145

146

147

148

149

150

151

152

153

154

155

156

157

158

159

160

161

162

163

164

165

rates of events from the included studies for comparison. Random-effects models were used to pool the estimates of primary and secondary outcomes from individual studies for each arm (TAx or DAo). In contrast to a fixed-effects model, a random-effects model enables the true underlying effect to vary among individual studies. $I^{2}$ above $25 \%, 50 \%$, and $75 \%$ were considered to represent low, moderate, and high heterogeneity across the studies, respectively (Higgins et al., 2003). The pooled estimates between TAx and DAo TAVR were compared using mixed-effects models. Statistical significance was set at $P<0.05$ with a two-tailed test. Data were analyzed using Comprehensive Meta-Analysis (version 2.2; Biostat, Englewood, NJ, USA).

\section{Results}

\section{Literature Search}

Our initial web-based literature search yielded 703 records. We screened the titles and abstracts of all 703 studies, of which 583 did not satisfy our inclusion and exclusion criteria. We downloaded and assessed the full-text of 120 articles for eligibility. After a review of the full-text articles, we excluded 19 articles that employed duplicated cohorts, 49 that did not report the outcomes of patients who received TAx or DAo TAVR, 13 that did not use VARC definitions for reporting the outcomes, 1 that included only TAVR with combined coronary artery bypass grafting procedure, 4 that used devices other than Edward or Medtronic, 1 that enrolled $<10$ cases, and 1 that employed a valve-in-valve procedure (Supplementary Material 2, Supplementary Table 2). Finally, we included 31 studies in the quantitative meta-analysis (Fig. 1), with 2883 and 2172 patients in the DAo TAVR and TAx TAVR groups, respectively (Adamo et al., 2015; Arai et al., 2016; Bonaros et al., 2017; Bruschi et al., 2017; Bruschi et al., 2015; Cocchieri et al., 2019; D'Ancona et al., 2019; Dahle \& Rein, 2014; Dahle, Kaneko \& McCabe, 2019; Damluji et al., 2018; Fiorina et al., 2016; Gilard et al., 2012; Gleason et al., 2018; Hysi et al., 2019; Jagielak et al., 2015; Khan et al., 2018; Laflamme et al., 2014; Muensterer et al., 2013; Okuyama et al., 2015; Petzina et al., 2017; Ramlawi et al., 2015; Ribeiro et al., 2015b; Romano et al., 2019; Ropponen et al., 2016; Schäfer et al., 2017; Spargias et al., 2014; Terzian et al., 2017; Testa et al., 2012; Thourani et al., 2015; Wendt et al., 2015; Zhan et al., 2020).

\section{Quality Assessment}

The quality of the 31 studies included in the meta-analysis was assessed using NOS, scored in the range of $0-8$ points. The NOS scores for all 31 studies ranged between 5 and 7 points, with a median score of 6 points (Supplementary Table 3).

\section{Baseline and Procedural Characteristics}

Table 2 presents the available baseline and procedural characteristics. The mean age of the DAo TAVR and TAx TAVR groups was $82.7 \pm 1.2$ and $80.0 \pm 1.7$ years, respectively. No substantial differences in logistic EuroSCORE (22.0 7.1 in DAo vs. $22.6 \pm 5.3$ in TAx) and STS score (7.5 
$166 \pm 1.8$ in DAo vs. $8.9 \pm 3.0$ in TAx) were noted. The percentage of MCV use in the TAx TAVR 167 group seemed to be higher than that in the DAo TAVR group.

\section{TAx and DAo TAVR Outcomes}

169 We analyzed the 2 primary outcomes, the 30-day stroke and mortality rates (Fig. 2). The 30-day

170

171

172

173

174

175

176

177

178

179

180

181

182

183

184

185

186

187

188

189

190

191

192

193

194

195

196

197

198

199

200

201

202

203

mortality rates of the DAo TAVR and TAx TAVR groups were significantly different with mortality rates of $9.6 \%$ [95\% confidence interval $(\mathrm{CI})=8.4 \%-10.9 \%]$ and $5.7 \%(95 \% \mathrm{CI}=$ $4.8 \%-6.8 \%$ ), respectively ( $P$ for heterogeneity $<0.001)$. The pooled 30 -day stroke rate in the DAo TAVR group $(2.6 \%, 95 \% \mathrm{CI}=1.9 \%-3.4 \%)$ was significantly lower than that in the TAx TAVR group $(5.8 \%, 95 \% \mathrm{CI}=4.9 \%-7.0 \% ; P$ for heterogeneity $<0.001)$.

We then analyzed secondary outcomes. Patients were more likely to require new PPM implantation after TAx TAVR $(20.1 \%, 95 \% \mathrm{CI}=15.5 \%-25.6 \%)$ than after DAo TAVR $(12.3 \%$, $95 \% \mathrm{CI}=9.4 \%-16.0 \%$; $P$ for heterogeneity $=0.009)$. Valve malposition occurred more frequently in patients who underwent TAx TAVR $(10.2 \%, 95 \% \mathrm{CI}=3.4 \%-27.1 \%)$ than in patients who underwent DAo TAVR $(2.0 \%, 95 \% \mathrm{CI}=0.9 \%-4.7 \% ; P$ for heterogeneity $=0.023)$. The conversion rate was higher in the DAo TAVR group $(2.8 \%, 95 \% \mathrm{CI}=2.1 \%-3.6 \%)$ than in the TAx TAVR group $(0.9 \%, 95 \% \mathrm{CI}=0.6 \%-1.6 \% ; P$ for heterogeneity $<0.001)$. No significant differences in the other secondary outcomes were identified between the 2 groups (Fig. 2).

\section{Discussion}

\section{TAx Versus DAo TAVR}

TAx TAVR is the most commonly used percutaneous, nonfemoral approach that does not require general anesthesia or endotracheal intubation. TAx TAVR is also less invasive than DAo and TA TAVR because it does not require entering the chest cavity, thereby reducing lung complication risks, thus shortening the ventilator time and intensive care unit stay.

In DAo TAVR, the delivery system enters directly through the ascending aorta, which requires minimal manipulation of the peripheral vessels, thereby reducing the incidence of peripheral vascular complications. Furthermore, cardiac surgeons are more familiar with DAo TAVR than with TA TAVR; therefore, DAo TAVR use may improve bleeding control and prevent myocardial injury, which can result in impaired ventricular function and ventricular pseudoaneurysm.

Data from more than 5,000 patients were analyzed in our systematic review and metaanalysis, which is the largest sample that has been used to compare TAx and DAo TAVR outcomes. We found that TAx TAVR was associated with a lower 30-day mortality rate, compatible with the findings of previous studies (Damluji et al., 2018; Fröhlich et al., 2015). Moreover, TAx TAVR was associated with higher postoperative stroke and PPM implantation rates than was DAo TAVR. Studies have reported similar trends; however, statistical significance was not demonstrated in these studies, which may be due to insufficient sample sizes (Adamo et al., 2015; Damluji et al., 2018; Fiorina et al., 2016; Fröhlich et al., 2015). 


\section{Stroke}

205 Post-TAVR stroke occurrence remains a major concern and cause of increased morbidity and

206

207

208

209

210

211

212

213

214

215

216

217

218

219

220

221

222

223

224

225

226

227

228

229

230

231

232

233

234

235

236

237

238

239

240

241 mortality. In the present meta-analysis, the stroke rate was higher in the TAx group than in the DAo group. The mechanism for the lower stroke rate after DAo TAVR is unclear. Transcranial Doppler studies have reported that cerebral embolism predominantly occurred during manipulation of the calcified aortic valve while prostheses were being positioned and implanted (Kahlert et al., 2012). The shorter distance and straight course between the device entry site (on the ascending aorta) and the aortic annulus of the DAo route may enable surgeons to implant the stented valve more accurately and rapidly with less aortic valve manipulation, resulting in fewer distal embolisms.

In contrast to DAo TAVR, TAx TAVR involves the advancement of the delivery catheter from the right or left subclavian artery to the ascending aorta, thus traversing the origins of the vertebral artery, carotid artery, aortic arch, and ascending aorta, which may induce atherosclerotic plaques and cerebral embolism. The flow of the vertebral artery or right carotid artery may be compromised during the procedure, particularly when the diameter of the innominate artery or left subclavian artery is only marginally wider than the delivery catheter. Moreover, TAx TAVR can cause vessel wall disruption along the innominate and subclavian arteries and the origins of the carotid and vertebral arteries, resulting in enhanced thrombogenicity, which may be linked to stroke (Barthélémy, Collet \& Montalescot, 2016).

\section{PPM Implantation}

A study comparing TAx and DAo TAVR in 4 high-volume Italian centers concluded that the TAx route is an independent predictor for increased PPM implantation (Fiorina et al., 2016) compatible with our finding that PPM implantation rate was higher after TAx TAVR than after DAo TAVR. Implantation depth is known to be a predictor of PPM implantation after TAVR. DAo TAVR may provide better control over device placement than does TAVR with peripheral access, potentially resulting in better coaxial alignment and more accurate implant depth, thereby causing fewer conduction disturbances (Bruschi et al., 2017). Large-scale studies reported that TA TAVR was associated with a significantly lower rate of PVL than was TF TAVR (Kodali et al., 2014; Van Belle et al., 2014). This finding suggests that more direct routes, such as DAo or TA, provide increased device placement control and thus lower PVL and PPM implantation rates. Furthermore, our meta-analysis indicated that TAx TAVR was associated with significantly higher valve malposition and numerically higher PVL compared with DAo TAVR $(P=0.113)$.

\section{Study Limitations}

First, all studies included in our analysis were observational, and thus, heterogeneity between the 2 groups was inevitable. However, the 2 groups cannot be accurately balanced without undertaking a randomized controlled trial. Second, to ensure the standardization of the definitions of stroke and other complications, we enrolled only the studies that used the VARC 
242 definitions; however, this limited the number of patients analyzed, thereby reducing the power of

243 the meta-analysis. Third, the pace of reporting does not match the rapid advancement of TAVR

244 technology; therefore, these results may not represent the real outcomes of the most recent

245 devices.

246

\section{Conclusions}

248 The present meta-analysis compared the outcomes of DAo and TAx TAVR. We determined that 249 the 30-day mortality rate was higher in patients who underwent DAo TAVR, but the

250 postoperative stroke and PPM implantation rates were higher in patients who underwent TAx

251 TAVR. Our findings could help TAVR candidates with unsuitable femoral access optimize their 252 selection of alternative access.

253

\section{Acknowledgments}

255 The authors thank Alfred Hsing-Fen Lin for his assistance with the statistical analysis.

256

257

258

259

260

261

262

263

264

265

266

267

\section{References}

Adamo M, Fiorina C, Curello S, Maffeo D, Chizzola G, Di Matteo G, Mastropierro R, Nardi M, Cervi E, De Cicco G, Chiari E, Curnis A, Bonardelli S, Coletti G, Manzato A, Metra M, and Ettori F. 2015. Role of different vascular approaches on transcatheter aortic valve implantation outcome: A single-center study. Journal of Cardiovascular Medicine 16:279-285. 10.2459/JCM.0000000000000252

Al-Attar N, Ghodbane W, Himbert D, Rau C, Raffoul R, Messika-Zeitoun D, Brochet E, Vahanian A, and Nataf P. 2009. Unexpected complications of transapical aortic valve implantation. The Annals of Thoracic Surgery 88:90-94.

10.1016/j.athoracsur.2009.03.070

Arai T, Romano M, Lefevre T, Hovasse T, Farge A, Le Houerou D, Hayashida K, Watanabe Y, 

Interventions 9:2320-2325. 10.1016/j.jcin.2016.08.009 College of Cardiology 68:600-602. 10.1016/j.jacc.2016.05.054

Bonaros N, Petzina R, Cocchieri R, Jagielak D, Aiello M, Lapeze J, Laine M, Chocron S, Muir Thoracic Surgery 51:919-926.

Bruschi G, Branny M, Schiltgen M, Ettori F, Marcheix B, Amrane H, Bushnaq H, Tan MESH, Direct Aortic Approach. The Annals of Thoracic Surgery 103:1434-1440. 10.1016/j.athoracsur.2016.08.080 
T, Fratto P, Nonini S, Soriano F, Mondino M, Giannattasio C, and Klugmann S. 2015.

287

Right anterior mini-thoracotomy direct aortic self-expanding trans-catheter aortic valve

implantation: A single center experience. International Journal of Cardiology 181:437-

289

442. https://dx.doi.org/10.1016/j.ijcard.2014.11.108

290

Chandrasekhar J, Hibbert B, Ruel M, Lam BK, Labinaz M, and Glover C. 2015. Transfemoral vs

291

292

293

Non-transfemoral Access for Transcatheter Aortic Valve Implantation: A Systematic

Review and Meta-analysis. Canadian Journal of Cardiology 31:1427-1438.

294

Cocchieri R, Petzina R, Romano M, Jagielak D, Bonaros N, Aiello M, Lapeze J, Laine M,

295 10.1016/j.cjca.2015.04.023

296

D'Ancona G, Ince H, Raspé C, Öner A, Caglayan E, Safak E, and Bushnaq H. 2019. Transaortic transcatheter aortic valve implantation: Learning curve, perioperative, and midterm follow-up results of a single center. Heart Surgery Forum 22:E134-E139. 
304 Dahle G, and Rein KA. 2014. Direct aorta ascending approach in transcatheter aortic valve

305 implantation. Innovations (Phila) 9:1-9.

$306 \quad$ https://dx.doi.org/10.1097/IMI.0000000000000046

307 Dahle TG, Kaneko T, and McCabe JM. 2019. Outcomes Following Subclavian and Axillary

308 Artery Access for Transcatheter Aortic Valve Replacement: Society of the Thoracic

309 Surgeons/American College of Cardiology TVT Registry Report. JACC: Cardiovascular

$310 \quad$ Interventions 12:662-669. 10.1016/j.jcin.2019.01.219

311 Damluji AA, Murman M, Byun S, Moscucci M, Resar JR, Hasan RK, Alfonso CE, Carrillo RG,

Williams DB, Kwon CC, Cho PW, Dijos M, Peltan J, Heldman AW, Cohen MG, and

313

Leroux L. 2018. Alternative access for transcatheter aortic valve replacement in older

314

adults: A collaborative study from France and United States. Catheterization and

Cardiovascular Interventions 92:1182-1193. 10.1002/ccd.27690

316 Fiorina C, Bruschi G, Testa L, De Carlo M, De Marco F, Coletti G, Bonardelli S, Adamo M, versus trans-aortic approach for transcatheter aortic valve implantation with corevalve revalving system: insights from multicentre experience. The Journal of Cardiovascular Surgery.

321 Fröhlich GM, Baxter PD, Malkin CJ, Scott DJA, Moat NE, Hildick-Smith D, Cunningham D, 
322 Maccarthy PA, Trivedi U, De Belder MA, Ludman PF, and Blackman DJ. 2015.

323 Comparative Survival after Transapical, Direct Aortic, and Subclavian Transcatheter

324 Aortic Valve Implantation (Data from the UK TAVI Registry). American Journal of Cardiology 116:1555-1559. 10.1016/j.amjcard.2015.08.035

326 Gargiulo G, Sannino A, Capodanno D, Barbanti M, Buccheri S, Perrino C, Capranzano P, Indolfi

327 C, Trimarco B, Tamburino C, and Esposito G. 2016. Transcatheter Aortic Valve

328 Implantation Versus Surgical Aortic Valve Replacement: A Systematic Review and

Meta-analysis. Annals of Internal Medicine 165:334-344. 10.7326/M16-0060

330

331

332

333

334

335

336

337

338

339

Gilard M, Eltchaninoff H, Iung B, Donzeau-Gouge P, Chevreul K, Fajadet J, Leprince P, Leguerrier A, Lievre M, Prat A, Teiger E, Lefevre T, Himbert D, Tchetche D, Carrié D, Albat B, Cribier A, Rioufol G, Sudre A, Blanchard D, Collet F, Dos Santos P, Meneveau N, Tirouvanziam A, Caussin C, Guyon P, Boschat J, Le Breton H, Collart F, Houel R, Delpine S, Souteyrand G, Favereau X, Ohlmann P, Doisy V, Grollier G, Gommeaux A, Claudel JP, Bourlon F, Bertrand B, Van Belle E, and Laskar M. 2012. Registry of transcatheter aortic-valve implantation in high-risk patients. New England Journal of Medicine 366:1705-1715. 10.1056/NEJMoa1114705

Gleason TG, Schindler JT, Hagberg RC, Deeb GM, Adams DH, Conte JV, Zorn GL, Hughes GC, Guo J, Popma JJ, and Reardon MJ. 2018. Subclavian/Axillary Access for Self- 
343 Grover FL, Vemulapalli S, Carroll JD, Edwards FH, Mack MJ, Thourani VH, Brindis RG,

Higgins JP, Thompson SG, Deeks JJ, and Altman DG. 2003. Measuring inconsistency in metaJournal of the American College of Cardiology 69:1215-1230. 10.1016/j.jacc.2016.11.033 Peripheral Vascular Disease. Seminars in Thoracic and Cardiovascular Surgery 31:175180. 10.1053/j.semtcvs.2018.09.016 Rogowski J, and Kozaryn R. 2015. Transaortic transcatheter aortic valve implantation: 
358

359

360

361

362

363

364

365

366

367

368

369

370

371

372

373

374

375

Results of the Polish arm of the ROUTE registry. Cardiology Journal 22:651-656.

https://dx.doi.org/10.5603/CJ.a2015.0046

Kahlert P, Al-Rashid F, Dottger P, Mori K, Plicht B, Wendt D, Bergmann L, Kottenberg E, Schlamann M, Mummel P, Holle D, Thielmann M, Jakob HG, Konorza T, Heusch G, Erbel R, and Eggebrecht H. 2012. Cerebral embolization during transcatheter aortic valve implantation: a transcranial Doppler study. Circulation 126:1245-1255.

\subsection{1/CIRCULATIONAHA.112.092544}

Kappetein AP, Head SJ, Genereux P, Piazza N, van Mieghem NM, Blackstone EH, Brott TG, Cohen DJ, Cutlip DE, van Es GA, Hahn RT, Kirtane AJ, Krucoff MW, Kodali S, Mack MJ, Mehran R, Rodes-Cabau J, Vranckx P, Webb JG, Windecker S, Serruys PW, and Leon MB. 2012. Updated standardized endpoint definitions for transcatheter aortic valve implantation: the Valve Academic Research Consortium-2 consensus document. European Heart Journal 33:2403-2418. 10.1093/eurheartj/ehs255

Khan AA, Kovacic JC, Engstrom K, Stewart A, Anyanwu A, Basnet S, Aquino M, Baber U, Garcia L, Gidwani U, Dangas G, Kini A, and Sharma S. 2018. Comparison of Transaortic and Subclavian Approaches for Transcatheter Aortic Valve Replacement in Patients with No Transfemoral Access Options. Structural Heart 2:463-468.

$10.1080 / 24748706.2018 .1497237$ 
376 Kodali S, Pibarot P, Douglas PS, Williams M, Xu K, Thourani V, Rihal CS, Zajarias A, Doshi D,

377

378

379

380

381

382

383

384

385

386

387

388

389

390

391

392

393
Davidson M, Tuzcu EM, Stewart W, Weissman NJ, Svensson L, Greason K, Maniar H, Mack M, Anwaruddin S, Leon MB, and Hahn RT. 2014. Paravalvular regurgitation after transcatheter aortic valve replacement with the Edwards sapien valve in the PARTNER trial: characterizing patients and impact on outcomes. European Heart Journal 36:449456. 10.1093/eurheartj/ehu384

Kodali SK, Williams MR, Smith CR, Svensson LG, Webb JG, Makkar RR, Fontana GP, Dewey TM, Thourani VH, Pichard AD, Fischbein M, Szeto WY, Lim S, Greason KL, Teirstein PS, Malaisrie SC, Douglas PS, Hahn RT, Whisenant B, Zajarias A, Wang D, Akin JJ, Anderson WN, and Leon MB. 2012. Two-year outcomes after transcatheter or surgical aortic-valve replacement. New England Journal of Medicine 366:1686-1695. 10.1056/NEJMoa1200384

Laflamme M, Mazine A, Demers P, Lamarche Y, Ibrahim R, Asgar A, and Cartier R. 2014. Transcatheter aortic valve implantation by the left axillary approach: A single-center experience. The Annals of Thoracic Surgery 97:1549-1554.

10.1016/j.athoracsur.2013.11.019

Leon MB, Piazza N, Nikolsky E, Blackstone EH, Cutlip DE, Kappetein AP, Krucoff MW, Mack M, Mehran R, Miller C, Morel MA, Petersen J, Popma JJ, Takkenberg JJ, Vahanian A, 
394

395

396

397

398

399

400

401

402

403

404

405

406

407

408

409

410

411 Muensterer A, Mazzitelli D, Ruge H, Wagner A, Hettich I, Piazza N, Lange R, and Bleiziffer S.

van Es GA, Vranckx P, Webb JG, Windecker S, and Serruys PW. 2011. Standardized

endpoint definitions for transcatheter aortic valve implantation clinical trials: a consensus

report from the Valve Academic Research Consortium. European Heart Journal 32:205-

217. 10.1093/eurheartj/ehq406

Leon MB, Smith CR, Mack MJ, Makkar RR, Svensson LG, Kodali SK, Thourani VH, Tuzcu

EM, Miller DC, Herrmann HC, Doshi D, Cohen DJ, Pichard AD, Kapadia S, Dewey T,

Babaliaros V, Szeto WY, Williams MR, Kereiakes D, Zajarias A, Greason KL,

Whisenant BK, Hodson RW, Moses JW, Trento A, Brown DL, Fearon WF, Pibarot P,

Hahn RT, Jaber WA, Anderson WN, Alu MC, Webb JG, and Investigators P. 2016.

Transcatheter or Surgical Aortic-Valve Replacement in Intermediate-Risk Patients. New

England Journal of Medicine 374:1609-1620. 10.1056/NEJMoa1514616

Makkar RR, Fontana GP, Jilaihawi H, Kapadia S, Pichard AD, Douglas PS, Thourani VH, Babaliaros VC, Webb JG, Herrmann HC, Bavaria JE, Kodali S, Brown DL, Bowers B, Dewey TM, Svensson LG, Tuzcu M, Moses JW, Williams MR, Siegel RJ, Akin JJ, Anderson WN, Pocock S, Smith CR, and Leon MB. 2012. Transcatheter aortic-valve replacement for inoperable severe aortic stenosis. New England Journal of Medicine 366:1696-1704. 10.1056/NEJMoa1202277

Peer) reviewing PDF | (2019:09:41000:1:0:NEW 25 Mar 2020) 
412

413

414

415 Okuyama K, Jilaihawi H, Mirocha J, Nakamura M, Ramzy D, Makkar R, and Cheng W. 2015.

416

417

418

419

420

421

422

423

424

425

426

427

428

429
2013. Safety and efficacy of the subclavian access route for TAVI in cases of missing

transfemoral access. Clinical Research in Cardiology 102:627-636. 10.1007/s00392-013-

0575-0
Alternative access for balloon-expandable transcatheter aortic valve replacement:

comparison of the transaortic approach using right anterior thoracotomy to partial Jsternotomy. The Journal of Thoracic and Cardiovascular Surgery 149:789-797.

https://dx.doi.org/10.1016/j.jtcvs.2014.10.062

Panchal HB, Ladia V, Amin P, Patel P, Veeranki SP, Albalbissi K, and Paul T. 2014. A metaanalysis of mortality and major adverse cardiovascular and cerebrovascular events in patients undergoing transfemoral versus transapical transcatheter aortic valve implantation using edwards valve for severe aortic stenosis. Am J Cardiol 114:18821890. 10.1016/j.amjcard.2014.09.029

Petzina R, Lutter G, Wolf C, Kuhl C, Freitag-Wolf S, Panholzer B, Bramlage P, Frey N, Cremer J, and Frank D. 2017. Transaortic transcatheter aortic valve implantation: experience from the Kiel study. Interactive CardioVascular and Thoracic Surgery 24:55-62. 10.1093/icvts/ivw277 
430

431

432

433

434

435

436

437

438

439

440

441

442

443

444

445

446

447
MT. 2015. Short-Term Outcomes with Direct Aortic Access for Transcatheter Aortic

Valve Replacement. The Journal of Heart Valve Disease 24:426-432.

Reardon MJ, Van Mieghem NM, Popma JJ, Kleiman NS, Sondergaard L, Mumtaz M, Adams

DH, Deeb GM, Maini B, Gada H, Chetcuti S, Gleason T, Heiser J, Lange R, Merhi W,

Oh JK, Olsen PS, Piazza N, Williams M, Windecker S, Yakubov SJ, Grube E, Makkar R,

Lee JS, Conte J, Vang E, Nguyen H, Chang Y, Mugglin AS, Serruys PW, Kappetein AP, and Investigators S. 2017. Surgical or Transcatheter Aortic-Valve Replacement in Intermediate-Risk Patients. New England Journal of Medicine 376:1321-1331.

10.1056/NEJMoa1700456

Ribeiro HB, Dahou A, Urena M, Carrasco JL, Mohammadi S, Doyle D, Le Ven F, Allende R, Amat-Santos I, Paradis JM, Delarochellière R, Puri R, Abdul-Jawad Altisent O, Del Trigo M, Campelo-Parada F, Pibarot P, Dumont É, and Rodés-Cabau J. 2015a. Myocardial injury after transaortic versus transapical transcatheter aortic valve replacement. The Annals of Thoracic Surgery 99:2001-2009.

10.1016/j.athoracsur.2015.01.029

Ribeiro HB, Dahou A, Urena M, Carrasco JL, Mohammadi S, Doyle D, Le Ven F, Allende R, Amat-Santos I, Paradis JM, DeLarochelliere R, Puri R, Abdul-Jawad Altisent O, del Trigo M, Campelo-Parada F, Pibarot P, Dumont E, and Rodes-Cabau J. 2015 b. 
448

449

450

451

452

453

454

455

456

457

458

459

460

461

462

463

464

465
Myocardial Injury After Transaortic Versus Transapical Transcatheter Aortic Valve

Replacement. The Annals of Thoracic Surgery 99:2001-2009.

https://dx.doi.org/10.1016/j.athoracsur.2015.01.029

Romano M, Daprati A, Saitto G, Tizzano F, Le Houérou D, Donzeau-Gouge P, Farge A, Lefèvre T, Hovasse T, and Garatti A. 2019. Safety and effectiveness of a transaortic approach for TAVI: procedural and midterm outcomes of 265 consecutive patients in a single centre. Interactive CardioVascular and Thoracic Surgery. 10.1093/icvts/ivz269

Ropponen J, Vainikka T, Sinisalo J, Rapola J, Laine M, and Ihlberg L. 2016. Transaortic Transcatheter Aortic Valve Implantation as a Second Choice over the Transapical Access. Scandinavian Journal of Surgery 105:35-41.

Schäfer U, Deuschl F, Schofer N, Frerker C, Schmidt T, Kuck KH, Kreidel F, Schirmer J, Mizote I, Reichenspurner H, Blankenberg S, Treede H, and Conradi L. 2017. Safety and efficacy of the percutaneous transaxillary access for transcatheter aortic valve implantation using various transcatheter heart valves in 100 consecutive patients. International Journal of Cardiology 232:247-254. 10.1016/j.ijcard.2017.01.010

Spargias K, Bouboulis N, Halapas A, Chrissoheris M, Skardoutsos S, Nikolaou J, Tsolakis A, Mourmouris C, and Pattakos S. 2014. Transaortic aortic valve replacement using the Edwards Sapien-XT Valve and the Medtronic CoreValve: initial experience. Hellenic 
467 Terzian Z, Urena M, Himbert D, Gardy-Verdonk C, Iung B, Bouleti C, Brochet E, Ghodbane W,

468 Depoix JP, Nataf P, and Vahanian A. 2017. Causes and temporal trends in procedural deaths after transcatheter aortic valve implantation. Archives of Cardiovascular Diseases

471 Testa L, Brambilla N, Laudisa ML, De Carlo M, Lanotte S, Latini RA, Pizzocri S, Casavecchia

472 110:607-615. 10.1016/j.acvd.2016.12.008 subclavian approach as a feasible alternative for transcatheter aortic valve implantation with the CoreValve ReValving System. EuroIntervention 8:685-690. Aortic Valve Replacement in the United States. The Annals of Thoracic Surgery 100:1718-1726; discussion 1726-1717. https://dx.doi.org/10.1016/j.athoracsur.2015.05.010

483 Van Belle E, Juthier F, Susen S, Vincentelli A, Iung B, Dallongeville J, Eltchaninoff H, Laskar 
484

485

M, Leprince P, Lievre M, Banfi C, Auffray JL, Delhaye C, Donzeau-Gouge P, Chevreul K, Fajadet J, Leguerrier A, Prat A, Gilard M, and Teiger E. 2014. Postprocedural aortic regurgitation in balloon-expandable and self-expandable transcatheter aortic valve replacement procedures: Analysis of predictors and impact on long-term mortality: Insights from the France2 registry. Circulation 129:1415-1427.

10.1161/CIRCULATIONAHA.113.002677

Walther T, Hamm CW, Schuler G, Berkowitsch A, Kotting J, Mangner N, Mudra H, Beckmann A, Cremer J, Welz A, Lange R, Kuck KH, Mohr FW, Mollmann H, and Board GE. 2015. Perioperative Results and Complications in 15,964 Transcatheter Aortic Valve Replacements: Prospective Data From the GARY Registry. Journal of the American College of Cardiology 65:2173-2180. 10.1016/j.jacc.2015.03.034

Wells G, Shea B, O'Connell D, Peterson J, Welch V, Losos M, and Tugwell P. 2014. The Newcastle-Ottawa Scale (NOS) for assessing the quality of nonrandomised studies in meta-analyses. Available at http://www.ohri.ca/programs/clinical_epidemiology/oxford.htm.

Wendt D, Kleinbongard P, Knipp S, Al-Rashid F, Gedik N, El Chilali K, Schweter S, Schlamann M, Kahlert P, Neuhauser M, Forsting M, Erbel R, Heusch G, Jakob H, and Thielmann M. 2015. Intraaortic Protection From Embolization in Patients Undergoing Transaortic 
502 Transcatheter Aortic Valve Implantation. The Annals of Thoracic Surgery 100:686-691.

Zhan Y, Kawabori M, Lofftus S, Cobey F, Rastegar H, Weintraub A, and Chen FY. 2020. Right

Figure Legends

510

511

512

Figure 1. Flow of study selection process.

$\mathrm{CABG}=$ coronary arterial bypass grafting; $\mathrm{DAo}=$ direct aortic approach; $\mathrm{TAx}=$

513

514

515

516

517 transaxillary; VARC $=$ Valve Academic Research Consortium.

\section{Figure 2. Forrest plot of TAx and DAo TAVR outcomes.} The pooled incidence of mortality, stroke, and other complications of TAx and DAo TAVR. DAo = direct aortic; TAVR = transcatheter aortic valve replacement; TAx = transaxillary. 


\section{Table $\mathbf{1}$ (on next page)}

Study data

Basic information of studies included in the meta-analysis. DAo $=$ direct aortic; NA $=$ not available; VARC $=$ Valve Academic Research Consortium, TAx $=$ transaxillary, US $=$ the United States 
Table 1. Study data

\begin{tabular}{|c|c|c|c|c|c|c|c|c|}
\hline First author & Year & Locations/country & Study type & $\begin{array}{l}\text { No. of } \\
\text { centers }\end{array}$ & study period & Access & $\begin{array}{l}\text { Patient } \\
\text { number }\end{array}$ & VARC \\
\hline Khan & 2018 & US & Single center & 1 & $2013-2015$ & TAx, DAo & 51 & 2 \\
\hline Damluji & 2018 & US, France & Multi-center & 3 & $2008-2017$ & TAx, DAo & 84 & 2 \\
\hline Fiorina & 2016 & Italy & Multi-center & 4 & $2007-2014$ & TAx, DAo & 147 & 2 \\
\hline Adamo & 2015 & Italy & Single center & 1 & $2007-2014$ & TAx, DAo & 32 & 2 \\
\hline Zhan & 2020 & US & Single center & 1 & 2015-2018 & TAx & 10 & 2 \\
\hline Dahle & 2019 & US & Multi-center & NA & 2015-2018 & TAx & 1249 & 2 \\
\hline Hysi & 2019 & France & Single center & 1 & $2015-2017$ & TAx & 43 & 2 \\
\hline Gleason & 2018 & US & Multi-center & 45 & NA & TAx & 202 & 1 \\
\hline Terzian & 2017 & France & Single center & 1 & 2006-2014 & TAx & 36 & 1 \\
\hline Schäfer & 2017 & Germany & Multi-center & 2 & 2010-2016 & TAx & 100 & 2 \\
\hline Laflamme & 2014 & Canada & Single center & 1 & 2010-2012 & TAx & 18 & 2 \\
\hline Muensterer & 2013 & Germany & Single center & 1 & 2007-2011 & TAx & 40 & 2 \\
\hline Testa & 2012 & Italy & Single center & 1 & NA & TAx & 70 & 1 \\
\hline Gilard & 2012 & France & Multi-center & 34 & 2010-2011 & TAx & 184 & 1 \\
\hline Romano & 2019 & France & Single center & 1 & $2011-2014$ & DAo & 265 & 2 \\
\hline Cocchieria & 2019 & Eurpoe & Multi-center & 18 & 2013-2015 & DAo & 253 & 2 \\
\hline D'Ancona & 2019 & German & Single center & 1 & $2012-2014$ & DAo & 106 & 2 \\
\hline Petzina & 2017 & Germany & Single center & 1 & $2012-2014$ & DAo & 99 & 2 \\
\hline Bruschi & 2017 & Europe & Multi-center & 9 & $2012-2014$ & DAo & 92 & 2 \\
\hline
\end{tabular}




\begin{tabular}{llllccccc}
\hline First author & Year & Locations/country & Study type & $\begin{array}{c}\text { No. of } \\
\text { centers }\end{array}$ & study period & Access & $\begin{array}{c}\text { Patient } \\
\text { number }\end{array}$ & VARC \\
\hline Bonaros & 2017 & Europe & Multi-center & 18 & $2013-2015$ & DAo & 301 \\
Ropponen & 2016 & Finland & Single center & 1 & $2008-2014$ & DAo & 36 & 1 \\
Arai & 2016 & France & Single center & 1 & $2011-2014$ & DAo & 289 & 2 \\
Wendt & 2015 & Germany & Single center & 1 & $2012-2014$ & DAo & 30 & 1 \\
Thourani & 2015 & US & Multi-center & NA & $2011-2014$ & DAo & 868 & 2 \\
Ribeiro & 2015 & Canada & Single center & 1 & $2007-2015$ & DAo & 45 & 2 \\
Ramlawi & 2015 & US & Single center & 1 & $2011-2015$ & DAo & 78 & 2 \\
Okuyama & 2015 & US & Single center & 1 & $2007-2014$ & DAo & 51 \\
Jagielak & 2015 & Poland & Multi-center & NA & $2013-2014$ & DAo & 32 \\
Bruschi & 2015 & Italy & Single center & 1 & $2008-2013$ & DAo & 50 \\
Spargias & 2014 & Greece & Single center & 1 & NA & DAo & 2 \\
Dahle & 2014 & Norway & Single center & 1 & $2009-2013$ & DAo & 30 \\
\hline
\end{tabular}

2

3 Basic information of studies included in the meta-analysis.

$4 \mathrm{DAo}=$ direct aortic NA $=$ not available VARC $=$ Valve Academic Research Consortium, $\mathrm{TAx}=$ transaxillary, US $=$ the United

5 States. 


\section{Table 2 (on next page)}

Baseline and procedural characteristics of patients.

$\mathrm{DAo}=$ direct aortic; $\mathrm{TAx}=$ transaxillary $; \mathrm{SD}=$ standard deviation 
1 Table 2. Baseline and procedural characteristics of patients.

\begin{tabular}{lcccc}
\hline & \multicolumn{2}{c}{ DAo patients } & \multicolumn{2}{c}{ TAx patients } \\
\cline { 2 - 5 } Variable & $\begin{array}{c}\text { Available } \\
\text { data, } \mathrm{n}\end{array}$ & $\begin{array}{c}\text { Weight } \\
\text { mean } \pm \mathrm{SD}\end{array}$ & $\begin{array}{c}\text { Available } \\
\text { data, } \mathrm{n}\end{array}$ & $\begin{array}{c}\text { Weight } \\
\text { mean } \pm \mathrm{SD}\end{array}$ \\
\hline Age, year & 2236 & $82.7 \pm 1.2$ & 2136 & $80.0 \pm 1.7$ \\
Logistic EuroSCORE & 642 & $22.0 \pm 7.1$ & 681 & $22.6 \pm 5.3$ \\
STS score & 1161 & $7.5 \pm 1.8$ & 1737 & $8.9 \pm 3.0$ \\
Old Stroke, \% & 1957 & 12.1 & 1957 & 12.1 \\
Atrial fibrillation, \% & 1152 & 28.6 & 590 & 39.0 \\
Peripheral arterial disease, \% & 2035 & 41.6 & 1919 & 64.4 \\
Chronic kidney disease, \% & 1946 & 28.5 & 557 & 16.0 \\
Previous cardiac surgery, \% & 1961 & 23.6 & 870 & 23.5 \\
Left ventricular ejection fraction, \% & 1965 & $62.3 \pm 9.7$ & 311 & $52.1 \pm 1.6$ \\
Device (CoreValve, \%) & 2847 & 23.2 & 1852 & 29.3 \\
\hline
\end{tabular}

2

3 DAo $=$ direct aortic; TAx $=$ transaxillary; $\mathrm{SD}=$ standard deviation

4

5 
Figure 1

Flow of study selection process.

$\mathrm{CABG}=$ coronary arterial bypass grafting; $\mathrm{DAo}=$ direct aortic approach; $\mathrm{TAx}=$ transaxillary; VARC $=$ Valve Academic Research Consortium 

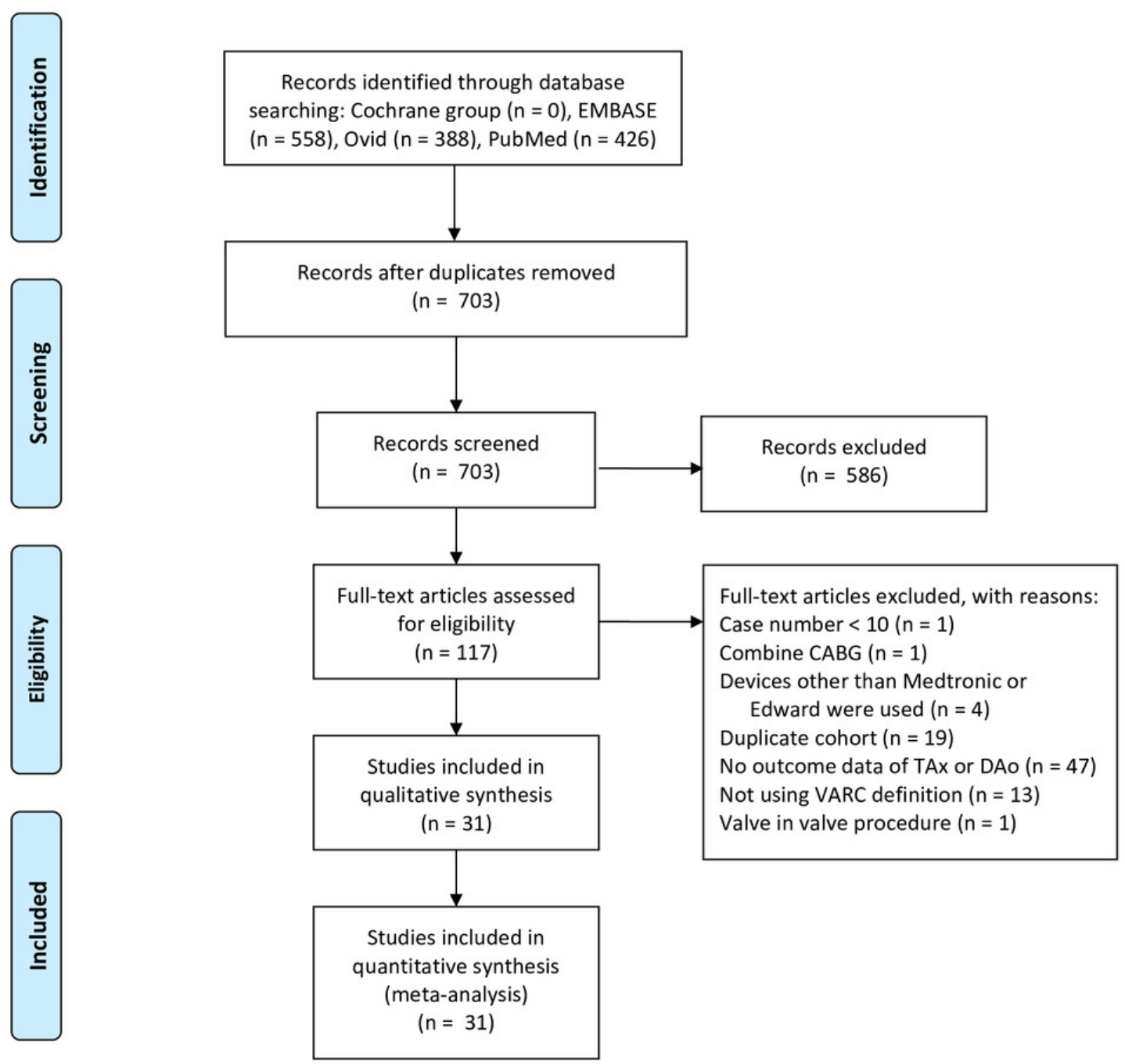
Figure 2

Forrest plot of TAx and DAo TAVR outcomes.

The pooled incidence of mortality, stroke, and other complications of TAx and DAo TAVR. DAo $=$ direct aortic; TAVR = transcatheter aortic valve replacement; TAx = transaxillary .

\begin{tabular}{|c|c|c|c|c|c|c|}
\hline Outcome / group & No. of study & $\begin{array}{l}\text { No. of event / } \\
\text { Total number }\end{array}$ & & Event rate, \% $(95 \% \mathrm{Cl})$ & $I^{2}(\%)$ & $\begin{array}{c}P \text { for } \\
\text { heterogeneity }\end{array}$ \\
\hline 30-Day mortality & & & & & & $<0.001$ \\
\hline DAO & 19 & $209 / 2335$ & $\diamond$ & $9.6(8.4-10.9)$ & 11.1 & \\
\hline TAx & 15 & $119 / 2172$ & $\diamond$ & $5.7(4.8-6.8)$ & 0.0 & \\
\hline 30-Day CV death & & & & & & 0.933 \\
\hline DAO & 8 & $32 / 715$ & $\diamond$ & $5.5(3.6-8.3)$ & 51.7 & \\
\hline TAx & 8 & $37 / 688$ & 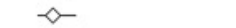 & $5.6(3.6-8.5)$ & 0.0 & \\
\hline 1-year mortality & & & & & & 0.600 \\
\hline DAO & 8 & $391 / 1493$ & $\leadsto$ & $22.8(18.2-28.1)$ & 70.7 & \\
\hline TAX & 7 & $107 / 517$ & $\infty$ & $20.7(15.4-27.3)$ & 33.4 & \\
\hline Stroke & & & & & & $<0.001$ \\
\hline DAO & 15 & $44 / 2035$ & $\diamond$ & $2.6(1.9-3.4)$ & 0.0 & \\
\hline TAX & 11 & $104 / 1879$ & $\diamond$ & $5.8(4.9-7.0)$ & 0.0 & \\
\hline AKI & & & & & & 0.461 \\
\hline DAo & 14 & $491 / 2177$ & $\leadsto$ & $11.7(6.8-19.3)$ & 94.2 & \\
\hline TAX & 9 & $62 / 520$ & $\infty$ & $8.2(3.7-17.3)$ & 61.8 & \\
\hline Major bleeding & & & & & & 0.283 \\
\hline DAO & 10 & $83 / 580$ & & $14.5(7.5-26.3)$ & 86.5 & \\
\hline TAx & 9 & $104 / 770$ & 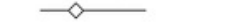 & $8.5(4.0-17.4)$ & 85.6 & \\
\hline Major vascular com & lication & & & & & 0.670 \\
\hline DAO & 12 & $45 / 1147$ & $\curvearrowright$ & $4.4(2.7-6.9)$ & 0.0 & \\
\hline TAX & 13 & $70 / 2096$ & $\curvearrowright$ & $3.8(2.3-6.2)$ & 70.9 & \\
\hline PPM & & & & & & 0.009 \\
\hline DAo & 15 & $161 / 1349$ & 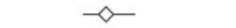 & $12.3(9.4-16.0)$ & 57.5 & \\
\hline TAX & 13 & $338 / 2119$ & 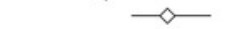 & $20.1(15.5-25.6)$ & 79.5 & \\
\hline PVL grade $2 / 3$ & & & & & & 0.113 \\
\hline DAO & 13 & $76 / 1223$ & 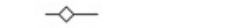 & $7.3(4.6-11.3)$ & 77.9 & \\
\hline TAx & 11 & $86 / 834$ & $\infty$ & $12.3(7.7-19.2)$ & 59.2 & \\
\hline Device unsuccess & & & & & & $0 . \overline{9} 43$ \\
\hline DAO & 15 & $73 / 1199$ & & $6.6(4.1-10.5)$ & 40.1 & \\
\hline TAX & 11 & $91 / 1851$ & & $6.8(3.8-11.8)$ & 85.0 & \\
\hline Conversion & & & & & & $<0.001$ \\
\hline DAO & 10 & $50 / 1885$ & $\diamond$ & $2.8(2.1-3.6)$ & 0.0 & \\
\hline TAX & 7 & $12 / 1740$ & $\diamond$ & $0.9(0.6-1.6)$ & 6.9 & \\
\hline Valve malposition & & & & & & 0.023 \\
\hline DAO & 7 & $5 / 488$ & $\diamond$ & $2.0(0.9-4.7)$ & 0.0 & \\
\hline \multirow[t]{2}{*}{ TAX } & 2 & $6 / 83$ & 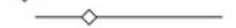 & $10.2(3.4-27.1)$ & 70.3 & \\
\hline & & & 10 & 30 & & \\
\hline
\end{tabular}

